American Journal of Applied Sciences 6 (4): 638-645, 2009

ISSN 1546-9239

(C) 2009 Science Publications

\title{
An Assessment of the Electric Power Quality and Electrical Installation Impacts on Medical Electrical Equipment Operations at Health Care Facilities
}

\author{
${ }^{1}$ Mário César Giacco Ramos and ${ }^{2}$ Carlos Márcio Vieira Tahan \\ ${ }^{1}$ University of Sao Paulo, 561 Aristeu Ribeiro de Resende Ave, Mogi das Cruzes, SP, Brazil 08790-000 \\ ${ }^{2}$ University of Sao Paulo, 158 Luciano Gualberto Ave, São Paulo, SP, Brazil 05508-900
}

\begin{abstract}
Problem statement: Medical electrical equipments at health care facilities presented malfunction and wrong medical information due to poor electric power quality and to inadequate electrical Installations. Some equipment such as X-ray, computerized axial tomography and magnetic resonance imaging are considered as polluting ones due to their high amount of harmonics and voltage transients produced on the electrical power supply when in operation, while other equipments, connected to the same power supply, are considered sensitive or victim ones, presenting failure or producing wrong. Approach: The effects on some sensitive medical electrical equipment were verified in a controlled environment at energy quality technological center of the technical school of the University of Sao Paulo. A heart monitor, pulmonary ventilator and pulse oxymeter equipment types were submitted to a controlled voltage supply with high harmonic content and voltage sags. The test methodology used simulated conditions based on Brazilian NBR standards, ANSI/IEEE Std. 519, IEC 60601 and IEC 61000-4-11 standards. Results: The results of the polluting equipment current consumption measurements as well as the three sensitive equipments tested were presented and discussed. The pulmonary ventilator presented problems that range from stoppage to expiratory valve blockage and alarm system failures. The pulse oxymeter presented display malfunctions and it was extremely sensitive to voltage sags. The heart monitor maintained steady operation in all test cases. Conclusion/Recommendations: In spite of several existing recommendations and standards for testing medical electrical equipments, there is a lack of standard related to test cases considering the effects of high harmonic and voltage sags. The quality of electrical installation in health care facilities needs to be improved to reduce risks to the patients and to provide better health treatment.
\end{abstract}

Key words: Electric power quality, electrical installations, medical electrical equipment installation, harmonic distortion and voltage sag

\section{INTRODUCTION}

Today advances in technology and development of medicine have been promoting great benefits to human health around the world. More and more frequently, new medical diagnostic processes and modern surgical techniques make use of state of the art equipment, designed and built with advanced electronic technologies and completely computerized.

In Brazil, to guarantee the safety of patients and to have reliable results, a medical equipment to be commercialized need to be registered at sanitary agency of the ministry of health, after being attested that it complies with applicable or mandatory national and international technical standards. The technical qualification of users and qualification of the staff in charge of the equipment maintenance are other important factors for safety and reliable results. However, a very important issue not too much stressed is to consider the electric power quality and the electrical installation within the health medical environments.

This study presents some test results obtained in a research laboratory on possible wrong medical diagnosis or risks to patient life based on electrical equipment fed in electrical power networks, which do not comply with the standards or are completely disturbed by other pieces of equipment typical of health-medical environments.

Another objective is to help equipment manufacturer to improve their products, showing them possible problems. Likewise, designers and people in

Corresponding Author: Mário César Giacco Ramos, University of Sao Paulo, 561 Aristeu Ribeiro de Resende Ave, Mogi das Cruzes, SP, Brazil 08790-000 Tel.: +55 1147961178 Fax: +55 1147967212 
charge of the electrical installation maintenance within health care facilities will be aware of the need to comply with applicable standards, avoiding improvised solutions which can cause risks to patients undergoing treatment or surgical intervention.

The electrical power quality can be determined by four basic electrical disturbances found in an electrical installation: voltage amplitude, signal frequency, voltage and current unbalances in three-phase systems and distortions on the signal waveform ${ }^{[1]}$.

Concerning the quality standards of electrical power supplied by the concessionary system, the relative absence of voltage amplitude variations is of great importance, especially the absence of power outages ${ }^{[2]}$. On the other hand, for the customer, the term quality of electrical power concerns, mostly, the relative absence of voltage amplitude variations as measured on the power delivery point.

In most cases, the disturbances are generated by the customers themselves, or by their neighborhood, due to the use of modern technology equipment based on nonlinear technology. Starting in the 1990s, the increasing use of these equipments through all segments of our society has made the situation worse under the aspect of the electrical power quality. In general, those pieces of equipment require a high-quality power supply for their perfect operation, but since they are the main generators of disturbances, they end up becoming their own $\operatorname{victims}^{[3]}$.

As far as medical electrical equipment is concerned, we can find a series of international standards such as IEC $60601^{[4]}$, which were the base for the elaboration of the Brazilian national standards NBR IEC 60601. This set of standards has the main purpose of establishing the minimum safety conditions and the performance of medical electrical equipments.

With regard to electrical installations, in a worldwide basis, one can find the IEC 60364 standard, electrical installations of buildings, as a general standard, which, in its part 7-710, deals with the requirements for electrical installations in medical facilities and associated areas ${ }^{[5]}$. In Brazil, in the same way, there are the NBR 5410-Low-Voltage Electrical Installations and NBR 13534-electrical installations in health care facilities standards. The latter became effective on December 29, 1995, with the purpose of establishing a set of minimum safety requirements for the electrical installations in health care facilities, such as hospitals, ambulatory care centers, medical and dental clinics, veterinary clinics, etc. Nowadays, NBR 13534 is being updated. The fourth issue of the NBR 5410 standard became effective on March 31, 2005.

\section{MATERIALS AND METHODS}

The existing standards do not consider the voltage harmonic and sags in the medical electrical equipment essays. Based on the measurements done at several hospitals and looking for how critical conditions the equipment can survive, some test scenarios were created.

The methodology applied consisted of taking measurements of parameters regarding of electrical power quality in health care facilities. Particular attention was paid to the voltage harmonic content and to momentary voltage transients, especially sags. The electrical current flow needed to operate three types of medical equipment usually found at typical health care facilities are measured during their operations. The purpose is to show the polluting characteristics of Xray, computerized axial tomography and magnetic resonance Imaging equipments. The field measurements were performed with a Fluke 43 B Energy Quality Analyzer, purchased especially for this purpose. Other measurement instruments have also been used, such as a Tektronix TD 1002 oscilloscope, among others.

Figure 1 shows an example of a polluting equipment current measurement and its impacts on the electric installation. The 83A peak currents provoke voltage sags of 5,1V reducing voltage amplitude from $214,5 \mathrm{~V}$ (average) to $209,4 \mathrm{~V}$.

Typical disturbances to those environments were reproduced at energy quality technological center of the polytechnical school of the University of Sao Paulo, known as Enerq-ct, using a special power supply. The main equipment responsible for generating voltage signals identical to the ones measured in the field is a power supply manufactured by Pacific Power Source, model 390 AMX with $9 \mathrm{kVA}$ output power.

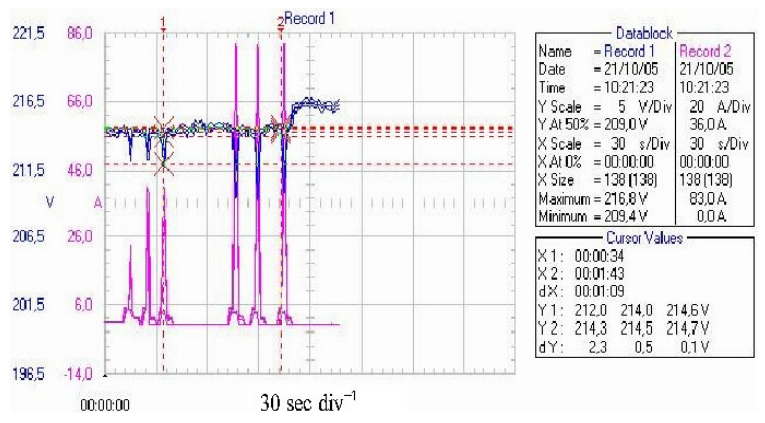

Fig. 1: Example of a polluting equipment current measurement with simultaneous electric power voltage measurement. The time scale is $30 \mathrm{sec} \operatorname{div}^{-1}$ 
It is equipped with UMC-31 three-phase controller, capable of generating frequencies between 45 and $500 \mathrm{~Hz}$. Once the magnitude is fixed, it has a steady operation, with $0.5 \%$ accuracy within predetermined values.

Portable medical electrical equipments, kindly provided by several national manufacturers, were subjected to these simulated conditions to have their performance verified. Some test cases, as those related to voltage sags, were complemented by tests established in IEC 61000-4-11 standard ${ }^{[6]}$.

Based on several existing test standards for medical equipments, three test sets were applied to heart monitor, pulmonary ventilator and pulse oxymeter and their results are synthesized and presented in the following results sections.

\section{RESULTS}

The current demand measurements were made during the operation of the X-ray, computerized axial tomography and magnetic resonance imaging equipments as follows. The fluke 43B energy quality analyzer measures the current consumption in Amperes during their typical image generation processes.

X-ray equipment current consumption measurements: Its use was a major breakthrough for diagnostic techniques, thanks to one of its features: high penetration, which permits the observation of internal organs without the need of surgery, either in Medicine or Biology. In mechanical or metallurgic industries, it allows the identification of internal cracks in metallic structures and in food industry the extension of the conservation period of perishable products. The production of X-rays is accomplished through a source that provides electrons, which are accelerated in a free trajectory until they collide with the atoms in a shield, promoting the displacement of electrons and consequent energy emission.

X-ray equipment has two operating modes: Continuous and momentary. During operation in momentary mode at the instant of radiography, there is a high demand for electrical power and temporary voltage sags can occur, compromising the performance of sensitive equipment connected to the power supply network. Figure 2 shows the current demand during the process of making radiographs. Current values up to 170A could be observed.

Computerized axial tomography current consumption measurements: It is one of the most reliable and safe methods of examination in modern
Medicine. It consists of X-ray equipment that turns around the patient's body, making transverse radiographs. Next, these radiographs are converted into tomography cuts by a computer, that is, a series of sections, which will later be assembled to form a complete image. Figure 3 shows current peaks of more than 90 A during its employment.

Magnetic resonance imaging current consumption measurements: Nowadays, Medicine can employ a precise and modern tool, with the purpose of obtaining a sectional image of the body internal structure. The image, obtained through magnetic properties, provides physicians with detailed data on location, size and composition of corporal tissue examined, allowing for a quick and accurate diagnosis. Magnetic resonance does not make use of X-rays. It uses the magnetic properties of atoms that constitute all substances, including obviously the human body. Through a powerful magnetic field generated by the equipment scanner,

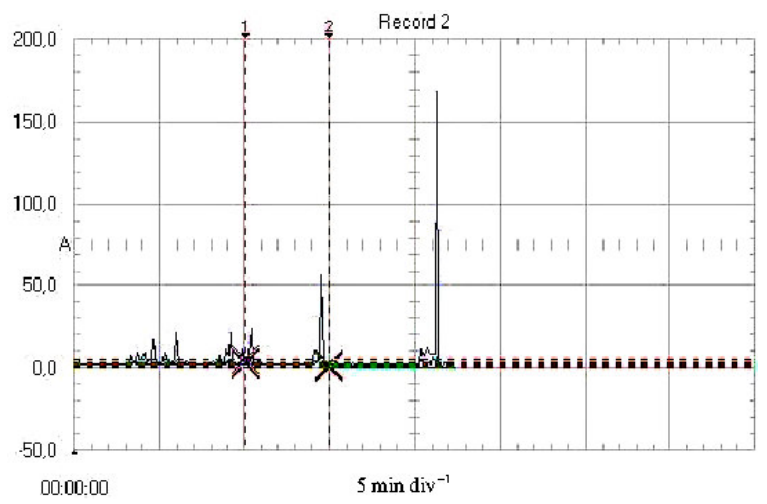

Fig. 2: Current peaks caused by X-ray equipment during its operation. The time scale is 5 min $\operatorname{div}^{-1}$

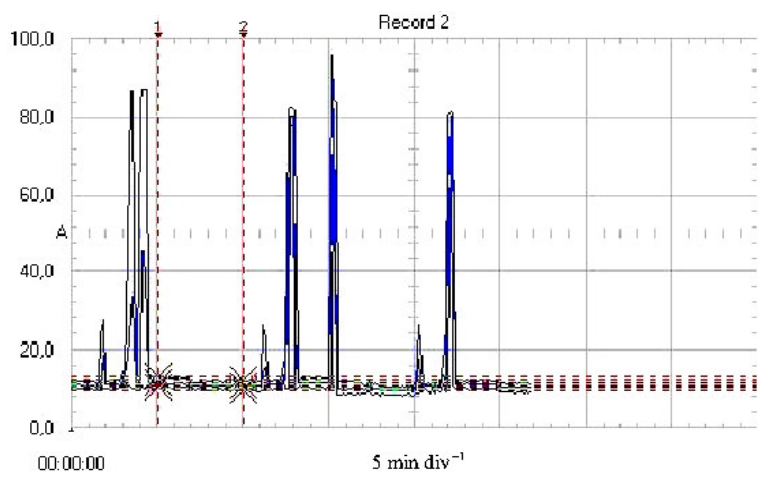

Fig. 3: Current peaks caused by computerized tomography equipment during its operation. The time scale is 5 min $\mathrm{div}^{-1}$ 


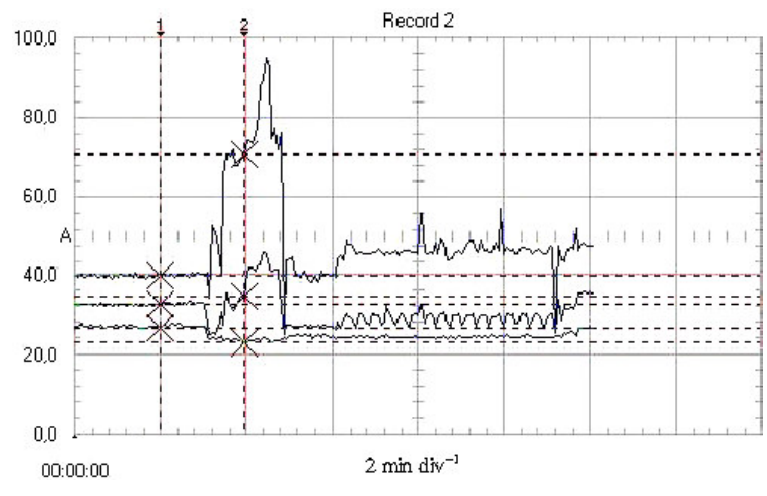

Fig. 4: Current peak caused by magnetic resonance imaging during its operation. The three graphics represents the maximum, average and minimum amplitude currents. The time scale is $2 \mathrm{~min} \mathrm{div}^{-1}$

electrical signals are emitted by the atomic nuclei of body tissues. A circular antenna surrounding the patient intercepts these signs. The intensity of the signal varies according to the kind of tissue. A computer assigns each signal to a point corresponding to the body area being examined and turns them into an image on the screen.

The current peak during its employment is shown in Fig. 4.

Sensitive equipment test results: Due to ease transportation, portable medical electrical equipments, frequently used in intensive care units or surgical centers, were tested. The tests were performed at the energy quality technological center of the technical school of the University of Sao Paulo. Up to the present, three types of sensitive medical electrical equipments were subjected to tests: Heart monitor, pulmonary ventilator and pulse oxymeter. The behaviors of such equipment when subjected to a voltage supply with a high harmonic content and under influence of voltage sags were assessed.

The first test set had the purpose of verifying the operation of the equipment when fed in a power supply containing voltage harmonics, as shown on Table 1.

The second test set related to momentary voltage sags, similar to those generated by $\mathrm{X}$ - ray, magnetic resonance and other equipments, whose values are shown on Table 2. Figure 5 shows an example of voltage sag sequence corresponding to the values from Table 2 to be applied to sensitive equipment.

In the third test set, voltage sags were applied according to IEC 61000-4-11 standard, item 5.1, whose values are shown in Table 3.
Table 1: Voltage harmonic distortion test set

\begin{tabular}{llrcrr}
\hline Test & $\begin{array}{l}\text { Fundamental } \\
(\%)\end{array}$ & $\begin{array}{l}\text { 3rd harmonic } \\
(\%)\end{array}$ & $\begin{array}{l}\text { 5th harmonic } \\
(\%)\end{array}$ & $\begin{array}{l}\text { 7th harmonic } \\
(\%)\end{array}$ & $\begin{array}{l}\mathrm{THD}_{\mathrm{f}} \\
(\%)\end{array}$ \\
\hline 1 & 100 & 3 & - & - & 3.0 \\
2 & 100 & 10 & - & - & 10.0 \\
3 & 100 & 20 & - & - & 20.0 \\
4 & 100 & 50 & - & - & 50.0 \\
5 & - & 100 & - & - & 100.0 \\
6 & 100 & 50 & 30 & 20 & 61.8 \\
7 & 100 & 70 & 50 & 30 & 91.5 \\
\hline
\end{tabular}

\begin{tabular}{lccll}
\multicolumn{2}{l}{ Table 2: Voltage sag test set } \\
\hline Test & $\begin{array}{l}\text { Voltage } \\
\text { sag (V) }\end{array}$ & $\begin{array}{l}\text { Remaining } \\
\text { voltage (V) }\end{array}$ & $\begin{array}{l}\text { Time of } \\
\text { duration }(\mathrm{sec})\end{array}$ & $\begin{array}{l}\text { Spacing } \\
(\mathrm{sec})\end{array}$ \\
\hline 1,2 and 3 & 60 & 50 & 0.5 & 20 \\
4 & 90 & 20 & 0.5 & - \\
5 and 6 & 100 & 10 & 0.5 & 20 \\
7 and 8 & 110 & 0 & 1.0 & 20 \\
9 & 60 & 50 & 1.0 & 20 \\
10 & 80 & 30 & 1.0 & 20 \\
11 & 100 & 10 & 1.0 & 20 \\
12 & 110 & 0 & 1.0 & 20 \\
\hline
\end{tabular}

Table 3: Voltage sag test set based on IEC 61000-4-11 standard

\begin{tabular}{lll}
\hline $\begin{array}{l}\text { Level of remaining } \\
\text { voltage }\left[\% \mathrm{U}_{\mathrm{n}}\right]\end{array}$ & $\begin{array}{l}\text { Voltage sag or } \\
\text { outage }\left[\% \mathrm{U}_{\mathrm{n}}\right]\end{array}$ & Duration [cycles] \\
\hline 80 & 20 & 0.515102550180 \\
70 & 30 & \\
40 & 60 & \\
20 & 80 & \\
0 & 100 & \\
\hline
\end{tabular}

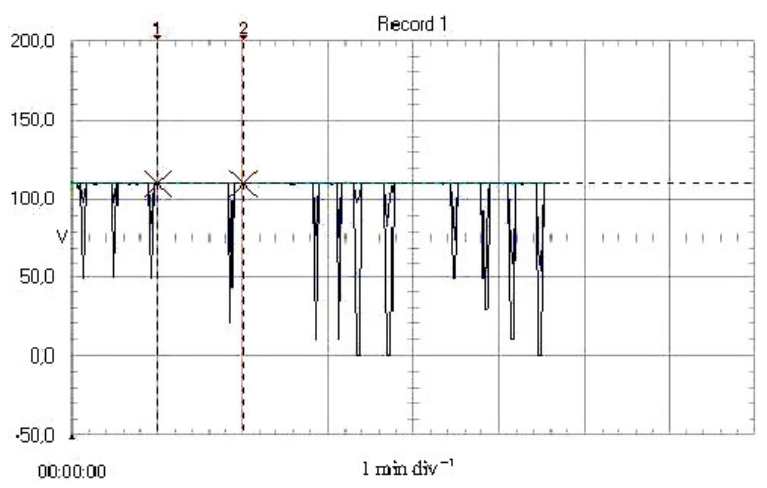

Fig. 5: Voltage sag sequence example to simulate the 12 test cases from Table 2

Heart monitor test results: The heart monitor is used for continual monitoring of a patient in surgical centers and intensive care units producing electrocardiograms as well as for monitoring temperature, breathing and other patient data. In addition to the waveform in the electrocardiogram, it can indicate the heart rate and provide important information like oxygen saturation levels in arterial blood $\left(\mathrm{SpO}_{2}\right)$ and arterial pressure. The equipment used in the tests performs those measurements in a non-invasive manner. 
Am. J. Appl. Sci., 6 (4): 638-645, 2009

A patient simulator was used to generate voltage pulses on a steady and regular basis, similar to those generated by a heart. The equipment tested has an internal battery for operation in cases of energy outages. In all tests, an $110 \mathrm{~V}$ voltage powered it. The maximum value obtained for the third harmonic voltage during measurements in several hospitals was 3\%, thus the values used during tests were far superior, with the objective to verify the behavior of the equipment under conditions that can be far more critical. For all the first test set, the heart monitor did not present interferences in the electrocardiogram waveform, what testifies the quality of the equipment with regard to this type of power supply disturbance.

For the second test set, the heart monitor did not present interferences on the signal generated on its screen. In the $10 \mathrm{~V}$ sag and $0 \mathrm{~V}$ (outage) with $1 \mathrm{~s}$ of duration, battery switchover occurred, but nevertheless, the signal on the screen was constant and steady.

During the third test set, all combinations of voltage sags and durations recommended by the IEC 61000-411 standard were applied. In all of them, the electrocardiogram signal was steady and without changes in its waveform. In the tests with $20 \%$ of remaining voltage, with duration of 180 cycles and outages with durations of 25,50 and 180 cycles, switchovers to the internal battery occurred, but no alterations in waveform could be seen on the equipment screen. It can be inferred that this piece of equipment keeps a steady operation when subjected to voltages with high harmonic content and critical momentary voltage sags.

Pulmonary ventilator test results: The ventilator type tested is completely microprocessor based and designed to be employed in respiratory insufficiency in pediatric and adult patients, with a body mass between 6 and $150 \mathrm{~kg}$. It is very practical equipment, with direct digital controls for the main ventilator parameters. The ventilation cycle starts by means of pressure and since it incorporates a ventilation monitor, it allows for an extensive monitoring of patient's conditions, increasing safety. Besides, an audiovisual alarm system with written messages on the control screen gives quick alarm identification. The presence of lungs was simulated through the use of a rubber balloon, provided by the manufacturer for this purpose.

In the first test set, the equipment was fed with $110 \mathrm{~V}$ nominal voltage, but with harmonic contents, as presented on Table 1. Although one can observe an important alteration in current waveform between sine voltage and the supply with completely distorted voltage, no alterations in the regularity of the equipment's ventilation cycles could be noticed.
Table 4: Voltage sag test set applied to pulmonary ventilator

\begin{tabular}{llllll}
\hline Test & $\begin{array}{l}\text { Quantity } \\
\text { of sags }\end{array}$ & $\begin{array}{l}\text { Voltage } \\
\text { of sag (V) }\end{array}$ & $\begin{array}{l}\text { Remaining } \\
\text { voltage (V) }\end{array}$ & $\begin{array}{l}\text { Duration } \\
(\mathrm{sec})\end{array}$ & $\begin{array}{l}\text { Spacing } \\
(\mathrm{sec})\end{array}$ \\
\hline 1 & 10 & 11 & 99 & 3 & 1 \\
2 & 10 & 22 & 88 & 3 & 1 \\
3 & 10 & 33 & 77 & 3 & 1 \\
4 & 10 & 44 & 66 & 3 & 1 \\
5 & 10 & 55 & 55 & 3 & 1 \\
6 & 10 & $11-110$ & $99-0$ & 3 & 60 \\
\hline
\end{tabular}

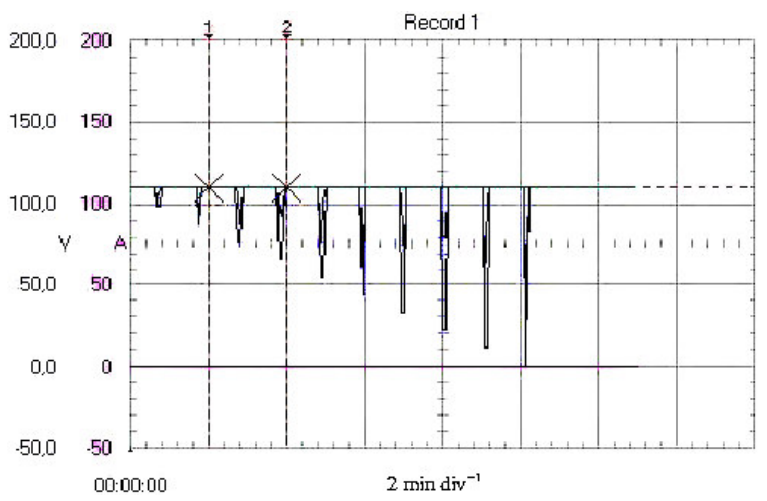

Fig. 6: Voltage sag sequence generation to simulate test 6 conditions of the Table 4

The digital manometer, installed in the frontal part, indicated the same values in all tests. In this way, the equipment's immunity to sharply distorted voltages could be attested.

The second test set related to momentary voltage sags, similar to those generated by X-ray equipment, magnetic resonance and others, used values shown on Table 4. Figure 6 shows the voltage sag sequence corresponding to the test 6 of the Table 4 . In test 6 , the equipment presented irregular operation for 77,88 and $99 \mathrm{~V}$ voltage sags and outage. Problems showed included stoppage, expiratory valve blockage and nonoperation of the alarm system.

In the 3rd test set, voltage sags following recommendations IEC 61000-4-11 standard were applied. Pressure and airflow figures were monitored with a flow meter connected to the equipment's exit duct (inhalation circuit). The equipment withstood, without alterations, sags of 20,30 and $60 \%$ for all durations, that is to say, from $0.5-180$ cycles. The same occurred for $80 \%$ voltage sag and outages with durations of $0.5,1$ and 5 cycles. On the other hand, either for sags of $80 \%$ or for outages with duration superior to 10 cycles, the equipment presented several problems, which might put at risk the patient connected to it: 
- The operation was interrupted, in spite of the battery being fully charged. Adjusted parameters were not lost, but alarm did not sound

- In some tests, depending on the instant when sags or outages were applied, the expiratory valve remained permanently opened, releasing into the environment all air/oxygen injected into the lungs. The alarm system also did not sound and the equipment had to be disconnected from the power supply and reprogrammed to resume operation

- In the same way as in case 2 , in some tests, the equipment halted and kept injecting air/oxygen with the expiratory valve completely shut. The alarm did not sound and the equipment also had to be disconnected from the power supply and reprogrammed. The pressure gauge indicated an increase, which was far superior to the supportable levels for the lungs of a human being

Pulse oxymeter test results: The pulse oxymeter measures the oxygen saturation levels $\left(\mathrm{S}_{\mathrm{p}} \mathrm{O}_{2}\right)$ in arterial blood, being this accomplished in a non-invasive manner, through optical sensors positioned externally to the patient. The use of the pulse oxymeter is considered standard procedure for monitoring blood oxygen saturation levels in intensive care units, surgical centers, post surgical recovery, units for patients with severe burns, units for catheterization and in ambulances. Its non-invasive characteristics render blood sampling and laboratorial analysis unnecessary. Another favorable feature is the possibility of monitoring blood oxygen levels, continuously and in real time, allowing for the prompt detection of eventual reductions in those levels, which could lead to risks to the patient. Blood color varies in function of oxygenation levels; blood with a high oxygen concentration being bright red. The presence of carbon dioxide alters blood color, tending to a slightly blueish color. Its operation is based on blood spectrophotometry, which measures light transmitted or reflected by capillaries within the human body, synchronized with the heartbeats.

The equipment tested was provided by a national manufacturer and does not have a battery to guarantee its operation during power outages. It is microprocessor-based equipment with alarm system activated when pre-established parameter are changed.

In the first test set with harmonic content, the behavior of the equipment changed, experiencing a very critical moment. The great influence of the 3rd harmonic could be observed, since values up to $50 \%$ of the fundamental generated interferences on the equipment display. For figures above $70 \%$ the equipment resumed normal operation. The 5th and 7 th harmonics had little influence in the final results, pre dominating the presence of the 3rd harmonic.

The 2 nd test set related to momentary voltage sags, similar to those generated by X-ray equipment, magnetic resonance and others, whose values are shown on Table 5.

In test there were no observable abnormalities. In tests 2 and 3, the display was slightly dim, but displayed values were not altered. In tests 4 and 5, the equipment presented a blinking screen and the values displayed decreased until the alarm actuated. The equipment had to be disconnected from power supply to resume operation.

For the third test set with voltage sags in accordance to IEC 61000-4-11 standard, the equipment presented several problems as detailed in the Table 6. This equipment is extremely sensitive to voltage sags.

\begin{tabular}{llllll}
\multicolumn{6}{l}{ Table 5: Voltage sag test set applied to pulse oxymeter } \\
\hline Test & $\begin{array}{l}\text { Quantity } \\
\text { of sags }\end{array}$ & $\begin{array}{l}\text { Voltage } \\
\text { of sag (V) }\end{array}$ & $\begin{array}{l}\text { Remaining } \\
\text { voltage (V) }\end{array}$ & $\begin{array}{l}\text { Duration } \\
(\mathrm{sec})\end{array}$ & $\begin{array}{l}\text { Spacing } \\
(\mathrm{sec})\end{array}$ \\
\hline 1 & 10 & 3.3 & 106.7 & 1 & 1 \\
2 & 10 & 5.5 & 104.5 & 1 & 1 \\
3 & 10 & 8.8 & 101.2 & 1 & 1 \\
4 & 10 & 11.0 & 109.0 & 1 & 1 \\
5 & 10 & 22.0 & 88.0 & 1 & 1 \\
\hline
\end{tabular}

Table 6: Pulse oxymeter occurrences resulted from voltage sag application according to IEC 61000-4-11 standard

\begin{tabular}{|c|c|c|c|}
\hline $\begin{array}{l}\text { Remaining voltage } \\
\text { level }\left[\% \mathrm{U}_{\mathrm{n}}\right]\end{array}$ & $\begin{array}{l}\text { Voltage sag or } \\
\text { outage }\left[\% U_{n}\right]\end{array}$ & $\begin{array}{l}\text { Duration } \\
\text { [cycles] }\end{array}$ & Occurrences \\
\hline 80 & 20 & $\geq 5$ & dimmed display, but no data loss occurred \\
\hline 70 & 30 & $\geq 5$ & dimmed display, but no data loss occurred \\
\hline 40 & 60 & 10 & $\begin{array}{l}\text { Equipment halted and screen displayed random characters. It had to be switched } \\
\text { off to resume operation }\end{array}$ \\
\hline 40 & 60 & 25,50 and 180 & Shut down but returned to main screen. Resumed normal operation \\
\hline 20 & 80 & $\geq 10$ & $\begin{array}{l}\text { Equipment halted and screen displayed random characters. It had to be switch } \\
\text { off to resume operation }\end{array}$ \\
\hline 0 & 100 & $\geq 10$ & $\begin{array}{l}\text { Equipment halted and screen displayed random characters. It had to be switch } \\
\text { off to resume operation }\end{array}$ \\
\hline
\end{tabular}




\section{DISCUSSION}

The polluting equipment measurements and its impacts into the sensitive medical electrical equipment behavior are assessed, showing the extreme importance of the electric power and installation quality in the health care facilities ${ }^{[7]}$. One can realized that electricity in the hospital environment is a source of life, capable of interfering with the patient's ability to survive or not, through the employment of pulmonary ventilation equipment, infusion pumps, lights for surgical illumination, emergency power, compressed air, oxygen, among others.

Other equipment, in spite of not being linked to the patient's survival abilities, makes use of electrical power to provide important information concerning the therapeutic treatment, such as laboratory equipment, imaging and physiotherapy equipment, or others, which may compromise patient's health. Moreover, a great deal of information is stored in computerized systems, frequently interconnected through networks, on such a way that aspects related to the quality of the electrical power become extremely important.

As previously mentioned, most disturbances are generated within the health care facility, by commutation of high-power loads, speed variators for induction motors and mainly by pieces of equipment specific to those environments.

Technological advance is implying a greater use of sensitive equipment in all segments of society, but unfortunately, detrimental regarding aspects related to quality of electrical power. As far as medical electrical equipment is concerned, either connected to a patient or providing data on his conditions, the result can be compromising. In the latter case, due to incorrect information, inadequate medical procedures can be applied, compromising the patient's life.

Unfortunately, there are no statistical data regarding those situations, but what is the acceptable failure rate when dealing with human lives? It can be concluded, therefore, the criticality of the problem, once safety is usually linked to high investments. Even to obtain such kind of statistics using laboratory controlled environment to improve the situation, several manufacturers refused to supply their equipment for testing, fearing that problems subject to legal implications could be found due to medical errors caused by malfunctions on such equipment; difficulties to get the right authorization for carrying out measurements in health care facilities aiming at determining polluting loads which deteriorate the quality of electrical energy or to attest the conformity of the electrical installations with applicable standards.
In spite of existing recommendations and standards for testing medical electrical equipments, there is a lack of standard considering the effects of high harmonic contents and voltage sags.

Specifically, regarding to medical electrical equipment, there are no studies concerning their interaction with electrical installations in health care facilities and the quality of the electrical energy supplied to these facilities. Many of these facilities have electrical installations that are completely adapted and in disagreement with NBR 13534. On the other hand, the same standard does not specify maximum figures for disturbances in those facilities, raising doubts on the information provided by the medical electrical equipment, either for diagnostic or medical treatment purposes. Recently, the Brazilian energy quality association was founded and this effort could establish disturbance limits and improve the NBR 13534 standard.

In Brazil, ANVISA-national sanitary agency is the agency within the Ministry of Health responsible for coordinating the enforcement of that standard. Through its state-departments, it gives official approval to electrical installation projects for health care facilities. Many of the problems related to electrical power quality are generated within customer's installations, due to high-power load commutation or to extensive use of induction motor speed variators. Several international organizations have standards on this issue, but a consensus among them is yet to be achieved.

Therefore, there is a need to develop research on sensitive equipment and its interaction with other systems connected to electrical power supply. Although, any rules on this subject or an appropriate legislation are not available in Brazil yet.

Some limitations for harmonic distortion, flicker severity and voltage unbalance can be found in the report criteria and procedures for supplying specialloads customers, developed by the Coordinating group of eletrobras electrical systems planning, first issue in March 1993. In the international field, the limitations for harmonic distortions are mentioned in ANSI/IEEE Std $519-1992^{[8]}$ and IEC 61000-3-2-2001 ${ }^{[9]}$ standards.

The objective of this technical article was not to teach how to design electrical installations or how to maintain them within acceptable standards, but to present factors, which may contribute to their deterioration, by presenting real cases witnessed by the authors themselves, during field research. In Brazil, general regulations for low-voltage electrical installations are found in NBR 5410, whose latest issue became effective in March of 2005. NBR 13534 
complements the previous standard in case of electrical installations in Health care facilities.

With regard to safety work, the new NR-10-safety in installations and services on electricity, pushed Brazil to the same level of international standards. The standard is objective and aimed to the worker, who plays the most important role in the production processes within companies, regulating clearly the employment of the correct techniques in installations and in services with electricity so as to preserve life and assure that the working environments can become safer.

Particular attention must be paid to the ground connection system, as a way of guaranteeing the continuity of electrical power supply on a steady manner, assuring the proper performance of the protection devices and preserving personal safety with regard to electrical accidents ${ }^{[7]}$. Most electrical installations in health care facilities are treated with the same disregard, which can be observed in other activities, industrial, commercial or service-like. The lack of updated electrical diagrams, identification of command and control devices in panels, identification of grounding points, among others, are also some of the factors which compromise the good performance of installations and could cause accidents, frequently severe ones.

\section{CONCLUSION}

The present study demonstrated the importance of the quality of electrical power within health care facilities. The disturbances to which medical electrical equipments were subjected may have origin within the installations in these same facilities, as well as in the distribution systems of concessionaires of electrical power supply. In other circumstances, poor design or maintenance also might contribute to medical electrical equipment malfunctions. On the other hand, with the knowledge provided by these kinds of tests, manufacturers should concentrate their efforts in improving their equipment, aiming at reducing sensitivity to such disturbances. Similarly, electrical power concessionaires will possess a better knowledge on problems caused by poor electrical power quality supplied to consumers of health-medical area.

\section{ACKNOWLEDGMENT}

The researchers thank to the energy quality technological center of the polytechnical school of the University of Sao Paulo for providing resources and instruments to test medical electrical equipments as reported in this research as well as instruments to evaluate some health care facility electrical installations. The authors thank to equipment manufacturers and hospitals for their support to this research.

\section{REFERENCES}

1. Dougherty, J.G. and W.L. Stebbins, 1997. Power quality: A utility and industry perspective. Proceeding of the Conference on Textile, Fiber Film Industry Technical, May 6-8, IEEE Computer Society, Washington DC., USA., pp: 1-10. DOI: 10.1109/TEXCON.1997.598528

2. Sersen, E. and J. Vorsic, 2008. Quality of Electricity Supply as a Service. The Energy Agency of the Republic of Slovenia. http://www.icrepq.com/icrepq-08/235-sersen.pdf

3. Barona et al., 2007. New power quality solutions especially designed for industrial applications. Proceeding of the 9th International Conference on Electrical Power Quality and Utilization, Oct. 9-11, IEEE Xplore Press, Barcelona, pp: 1-7. DOI: 10.1109/EPQU.2007.4424076

4. IEC Std. 60601, 2008. Electrical safety testing for medical equipment.

http://www.ruggedpcreview.com/3_definitions_60 601.html

5. IEC Std., 60364-7-710, 2002. Electrical Installations of Buildings - requirements for special installations or locations-Medical locations. http://webstore.iec.ch/preview/info_iec60364-7710\%7Bed1.0\%7Db.pdf

6. IEC Std., 61000-4-11, 2004. Testing and Measurement Techniques-voltage dips, short interruptions and voltage variations immunity tests. http://webstore.iec.ch/preview/info_iec61000-411\%7Bed2.0\%7Db.pdf

7. Keebler, P., 2007. Power quality for healthcare facilities. http://www.leonardoenergy.org/drupal/files/2008/PQTW_Power\%20Qu ality $\% 20$ for $\% 20$ Healthcare_euro.pdf?download

8. Hoevenaars, T. et al., 2003. Interpreting IEEE Std 519 and meeting its harmonic limits in VFD applications.

http://www.mirusinternational.com/downloads/PCI C-2003-15,\%20Interpreting\%20IEEEStd519.pdf

9. IEC Std., 61000-3-2, 2005. Harmonic limits for equipment with input currents $\leq 16$ A per phase. http://webstore.iec.ch/preview/info_iec61000-32\%7Bed3.0\%7Den_d.pdf 